\title{
A Chronicle of Change: The Core Values We Cherish
}

As we approach the last quarter of the year, it is time that Fellows of the Philippine Society of Otolaryngology-Head and Neck Surgery (PSOHNS) receive this report from the President and the Board of Trustees. Following the successful staging of the midyear congress at EDSA Shangrila and distribution of the coffeetable book-- another chronicle of our rich history-- we also witnessed the launching of the advocacy campaign "Change is in the Air" led by Philippine Academy of Rhinology (PAR) Chair Dr. Tony Chua with Drs. Mari Enecilla and Joel Romuladez that even saw print in the newspapers. Despite the challenges, the support we received from our pharmaceutical friends was tremendous and the avowed fund support for advocacy from the proceeds of that congress amounting to a little over P2 million will certainly go a long way for our future campaigns. Our new home and headquarters at 27 Manga Road, Quezon City was finally inaugurated last July 8. Legal ownership with the title of the property under the name of PSOHNS has been effected as has been approved by the general assembly with the funds related to our transfer and total expenses for minor renovation and transfer and other taxes amounting to an expenditure of almost P29 million. The tax-exempt certificate filed from our Medical

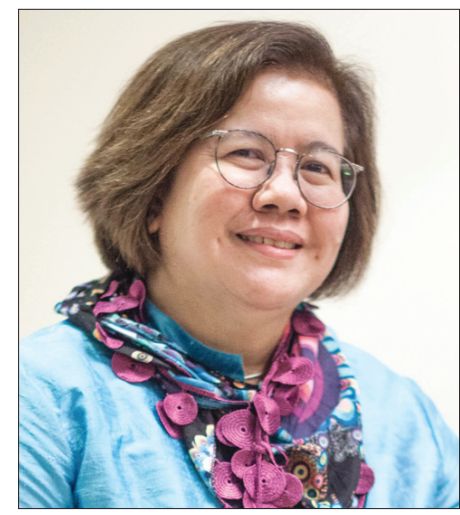
Plaza Ortigas business address will be transferred to Quezon City with the application for a change in business address.

There have already been activities, meetings and functions held at our new headquarters. As approved by the Board, we have invited the Philippine Board of Otolaryngology - Head and Neck Surgery (PBOHNS) to hold their meetings there and also hold office in one of the rooms. We expect full transfer by the time this tax-exempt certificate and occupancy permit have been obtained.

The work on becoming a recognized specialty by the Philippine Medical Association (PMA) is still a work in progress but the task is in hand more than ever with about 5000 more votes during the last congress and hopefully the final turnover of these votes before the next PMA convention in May 2017 will make the campaign a success. I urge all the Fellows and Chapters to continue to rally their colleagues and use the proxy forms available at the secretariat. We have written the PMA to inform us of the number of votes still needed. It is on record that our society in fact submitted the most number of proxy votes for this campaign during the last PMA convention. Let us all work even harder to make this a reality by May 2017.

The Professional Regulations Commission (PRC) and Philippine Regulatory Board of Medicine (PRBOM) required us last May to develop and submit an Outcomes Based Education (OBE) Curriculum. We submitted the required curriculum to the PRBOM led by Dr. Miguel Noche in cooperation and close collaboration with the PBOHNS led by Dr. Rodolfo Nonato through the commendable hard work of Drs. Agnes T. Remulla, Elmo Lago and Ed Alfanta as well as other committed fellows from the different subspecialties and institutions. Welcome changes to the required list and number of procedures for resident trainees as a result of the formulation of this new curriculum were approved. Our core values of Professionalism, Service with Excellence, Outstanding Education and Research, Honor and Integrity, Nationalism and Solidarity stood as pillars that guided the whole process of crafting this OBE. It will now be incumbent upon the institutions to tweak their instructional designs and particular curricula to conform to or even surpass the common minimum standards. We will bring to the table this curriculum and standards when we talk with our Association of South East Asian Nations (ASEAN) counterparts in the move to ASEAN Harmonization and Integration. The next midyear congress will be held in Laoag City under the leadership of Dr. Jose Orosa III. The next Annual Congress will be jointly held with the 10th International Symposium on Recent Advances in Rhinosinusitis and Nasal Polyposis from November 29- December 2, 2017 with PAR and Dr. Gil Vicente as prime mover. The Philippines will also host the $10^{\text {th }}$ Otorhinolaryngology International Academic Conference (ORLIAC) on March 1-3, 2018 with myself as co-chair. The theme will be "East Meets West: The Future of ORLHNS" with Prof. Jan Veldman and Prof. Lokman Saim helping organize this with world renowned ORL clinician-researchers willing to share their expertise on issues relevant to our country and the region. We hope this will inspire our young ENT diplomates and fellows to embark on academic and innovative strategies in the interest of achieving better care in ORLHNS.

The $60^{\text {th }}$ Annual Congress at Marriott Grand Ballroom from December 1-3, 2016 will culminate the celebration of our diamond jubilee year. The PSOHNS will host the $6^{\text {th }}$ Pan Asia Academy of Facial Plastic and Reconstructive Surgery in this joint Congress. We are excited at this year's theme: Restoring Form and Function and the record number of speakers for the congress with its interesting scientific and social programme will be astounding. As we close the year more projects are forthcoming such as the updated Clinical Practice Guidelines (Sleep Surgery has been disseminated with Otitis Media and Sinusitis to follow). On its $35^{\text {th }}$ year, the Philippine Journal of Otolaryngology Head and Neck Surgery's continued moves toward open access will make our research work more accessible and available to scientific circles worldwide.

We have recognized the loyalty and service of our personnel Mia, Sharon, Melissa and Kiko by a windfall increase in salaries and benefits that have long been overdue. We are now in the process of digitizing our records along with other housekeeping functions that we have embarked on this year. We also foresee a constitutional amendment to accommodate an expanded membership programme to be attuned with the mandate and direction of the Philippine Medical Association to be as inclusive as possible. The kind approval of the Fellows in the general assembly meeting is prayed for considering the fact that our scientific calendar and a lot of PSOHNS activities have been geared towards preparing the resident trainees, diplomates and non-diplomates and board eligibles to be dedicated Fellows of PSOHNS in the future, imbued with the core values we so cherish.

See you all soon and Mabuhay!

CHARLOTTE MARTINEZ CHIONG, MD, PHD

President

Philippine Society of Otolaryngology-Head and Neck Surgery 